\title{
ENTREVISTA COM PEDRO PEREIRA LOPES
}

Flávio Garcia (UERJ)

Flavio García é Professor associado da Universidade do Estado do Rio de Janeiro(UERJ), atuando na Graduação em Letras e no PPGLetras, na área de Estudos de Literatura, nas especialidades de Literatura Portuguesa e de Teoria da Literatura e Literatura Comparada, com orientações de mestrados e doutorado e supervisões de pós-doutorado. Desde agosto de 2014, é bolsista PROCIÊNCIA (UERJFAPERJ). Flavio García iniciou, em março de 2020, seu quarto pós-Doutorado, na área de Culturas e Literaturas Africanas de Língua Portuguesa da Faculdade de Letras da Universidade de Lisboa, intitulado "Figuração insólita de personagenstítulo em narrativas de Mia Couto admissíveis como literatura infantil e/ou juvenil?", sob a supervisão do Profa. Doutora Ana Mafalda Leite.

Lattes: http://lattes.cnpq.br/4242057381476599

ORCID iD: https://orcid.org/0000-0003-0761-8092 


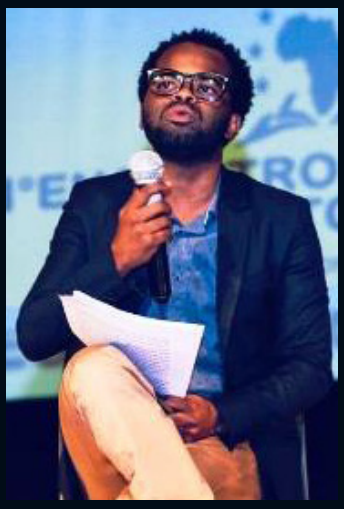

Pedro Pereira Lopes é um jovem, porém já bastante reconhecido e premiado, escritor moçambicano, nascido na província da Zambézia em 1987. Além de escritor, Pedro é professor e pesquisador da Universidade Joaquim Chissano, em Maputo, Moçambique. No Brasil, alguns de seus títulos encontram-se publicados pela Editora Kapulana ${ }^{1} \mathrm{e}$ pela Editora Desconcertos ${ }^{2}$.

Foram especialmente três questões que nos levaram a pedir-lhe esta entrevista, que ele muito prontamente concordou em nos conceder.

A primeira dessas questões adveio de seu conto infantil Kanova e o segredo da caveira, publicado em Moçambique em 2013, integrando o projeto "Contos e histórias de Moçambique", em parceria da Escola Portuguesa de Moçambique com a Fundação Contos para o Mundo de Barcelona. Em 2017, o conto foi publicado no Brasil, na série "Contos Moçambicanos" da Editora Kapulana. O projeto editorial brasileiro mantém as bases do projeto original.

Ao explicar a gênese desse conto, Pedro retoma sua matriz, que ele teria colhido em uma história que diz ter crescido ouvindo, "O rapaz e a caveira", mas cujo final pedagogicamente moralizante não lhe agradava. Assim, para recompensar sua infância, oferecendo às crianças de agora uma história que melhor condissesse com sua expectativa, reestruturou-a realçando-Ihe o caráter maravilhoso.

A segunda questão tem por referencial seu romance mundo grave, obra vencedora da 1 a edição do Prémio Instituto Nacional Casa da Moeda / Eugénio Lisboa em 2017 (Lisboa) e do Prémio Bunkyo de Literatura para ficção policial em 2019 (São Paulo). A 1ạ edição do livro data de 2018, mas, conforme se lê ao seu final, ele poderia ter sido concluído em 20 de março de 2013 (vai lá saber, pois pode ser metaficção...).

1 http://www.kapulana.com.br/

2 https://desconcertoseditora.com.br 
A crítica aponta aspectos que inscrevem o romance no universo da narrativa de investigação, mistério e policial, destacando, ainda, sua proximidade com o fantástico. Contudo, sua leitura traz à baila estratégias narrativas e temas que a permitem inscrever na seara do realismo animista.

A terceira daquelas questões é tanto mais específica, quanto mais geral. Nos "Comentários e agradecimentos" de mundo grave, Pedro diz "obrigado à Fernanda Angius, de quem tive as primeiras lições de escrita". Há uns quinze anos, em um evento internacional de literaturas africanas, realizado na Universidade Federal do Rio de Janeiro, apresentamos uma leitura de $A$ varanda do frangipani, à luz do insólito ficcional. Como sempre soe acontecer, fomos duramente criticados por pesquisadores brasileiros e portugueses que não admitem que se aborde a cultura, arte, a literatura africanas sob vieses do insólito. Ao final da apresentação, uma doce senhora veio falar conosco. Apresentou-se, deu-nos um cartão de visitas e nos disse que não nos importássemos com aqueles ataques. Ela ouvira da boca do próprio Mia Couto que muitas de suas narrativas se inscreviam naquela perspectiva, mas que, por razões outras, ele não ousaria dizer isso em público. Essa senhora é exatamente Fernanda Angius, a quem devemos o ânimo e o impulso para nossa caminhada.

Vamos, então, ao Pedro Pereira Lopes, nosso entrevistado para este $n=13$ da Revista Abusões, dedicado a'O insólito em narrativas de crime, mistério e investigação.

\section{P.: Pedro, você (vamos usar o você, caso não se importe, para mantermos nossa brasilidade) tem ideia de que as entrevistas dadas a revistas acadêmicas sempre podem incorrer em armadilhas para o entrevistado, não?}


R.: As entrevistas são como um labirinto, em desespero e, talvez, em despreparo, elas nos denunciam. É por tal razão que as evito ao máximo. Não gosto da capa de intelectualidade a que, como escritor, sou obrigado a vestir. E há, ainda, a preocupação de emitirmos uma opinião sobre quase tudo. Eu gosto de estar quieto, de ser quieto, de provocar de longe imerso na minha sozinhidão, como diria o Patraquim.

P.: Depois daquele alento que Fernanda Angius nos deu, o próprio Mia Couto, em alguns de seus artigos de opiniäo, publicados em Pensatempos e em Se Obama fosse africano..., e, mais recentemente, em entrevista dada à Revista Visão ${ }^{3}$, admite que a realidade africana, que nutre os mundos ficcionais, é maravilhosa, fantástica... Como você, na qualidade de ficcionista, que precisa do pano de fundo da realidade para compor seu real textual, se posicionaria acerca dessa questão?

R.: Toda "realidade" humana é maravilhosa, é fantástica, assim, por conseguinte, a sua ficção. Sempre foi bastante ténue a fronteira entre a realidade e a fantasia. O homem sempre se alicerçou em explicações mágicas para decifrar a sua realidade. Não há, aqui, novidade. Então, eu não aceito muito a ideia de uma "realidade africana maravilhosa e fantástica". Há alguns anos, comprei um pequeno livro, de capa desbotada, num alfarrabista de rua. O livro chamava-se Contos da chuva e da terra e tinha sido escrito por Ueda Akinari. Não tinha ainda lido o realismo mágico latino ou o Dr. Strange e o Senhor Norrell, de Susanna Clarke. Depois, vivi algum tempo na China e ouvi as 
suas histórias. O que difere as nossas realidades, nesse sentido, é algo delicado.

Alguns conceitos resumem uma mania dos críticos para identificar a "literatura africana", em associação à "África da oralidade", das fogueiras e das explicações mágicas e ilógicas. Sem essas características, deixaria de ser ficção africana? Então, posto desse modo, seria uma literatura oposta à literatura moderna. O Ungulani ba ka Khossa usa o conceito de "texto emancipado", autónomo, para explicar que narrador não pode copiar a realidade, mas criar uma nova realidade. Creio que é isso que mais importa.

P.: Mantendo-nos no mesmo eixo, você diria que, num primeiro momento do pós-independência das ex-colônias portuguesas e, no caso de Moçambique, no entorno à Guerra de Desestabilização (a guerra civil), escrever ficção insólita (maravilhosa, fantástica, real-animista...) era reprovável?

R.: Eu não diria "reprovável", mas não utilitária. Qual seria o papel de uma literatura insólita no período em alusão? A literatura de Moçambique nasce sob o signo da intervenção social, do realismo na sua forma mais dura. Era preciso denunciar o colonialismo, convocar e unir as pessoas, os leitores - esta era a missão da prosa proto-nacionalista e nacionalista, como é o caso de Nós matámos o cão tinhoso e, de certo modo, Portagem.

Com a independência e a guerra civil, fundamentados pela lógica do socialismo científico, a prosa toma a forma, essencialmente, do relato, com títulos como Duplo Massacre em Moçambique - Histórias Trágicas do Banditismo, da Lina 
Magaia, ou Relatos do povo armado, de Licínio de Azevedo. Só em finais dos anos 1980, com a institucionalização da economia do mercado, saem, pelo menos em livro, textos a que podemos chamar de realismo-mágico, o Vozes anoitecidas, do Mia Couto, o Ualalapi, do Ungulani, O regresso do morto, do Suleiman Cassamo e, depois, os romances da Paulina Chiziane. É uma literatura sem agendas, não comprometida, aliás, o seu único engajamento é com a arte, com um regresso às raízes, à convivência normal.

P.: Dando fecho a essa questão, agora, quando os sentimentos de pertença estão mais acalentados e as guerras (que ainda há) não implicam independência ou enfrentamento daquele outro exógeno, a cultura, a arte, a literatura moçambicanas (para nos fixarmos em Moçambique) podem, devem e se têm permitido avançar por outras opções de composição estética globalizadas, mundializadas?

R.: Sim. Na verdade, não nos esqueçamos que a literatura de Moçambique surge na língua do colonizador, primeiro, como uma forma de revolução e, depois, de afirmação de sua moçambicanidade. Então, pouco ou quase nenhum estranhamento houve com a literatura do exterior. O poema "Surge et ambula", por exemplo, do Rui de Noronha, é inspirado num poema de Antero de Quental. Noémia de Sousa e Craveirinha "inspiraram-se" nos blues, no jazz e na poesia do Renascimento Negro dos EUA. Durante os dias do socialismo, leu-se muito a literatura russa. Depois, o Jorge Amado, o Fernando Namora, entre outros realistas. O Guimarães Rosa, o Alejo Carpentier, o Garcia Márquez e Hemingway também. 
Hoje, com a globalização e a internet, os jovens estão ainda mais ousados. É uma geração experimentalista com influências antes inimagináveis. É uma literatura africana que se renova com a construção destes novos africanos. É uma literatura também cosmopolita, híbrida ou criola. Aliás, como diz o professor Nataniel Ngomane, "não existem literaturas puras".

P.: O seu mundo grave incorpora diversas e diferentes técnicas de composição, seja pelo năo emprego de maiúsculas, pela burla à pontuação, pelas inserções de parênteses com informações por vezes metaficcionais, pela explicitação da voz do narrador em meio à narrativa etc. Você diria que foi uma escolha over intencionada ou um acaso da escrita?

R.: Os estilos não são um mero fruto do acaso. A construção do discurso e da mancha gráfica do texto fazem parte de um exercício de escrita, de técnicas. Portanto, elas são intencionais. Sou uma mescla dos autores que fui lendo. mundo grave é a segunda parte de um projecto experimental que se inicia com o meu livro de contos o mundo que iremos gaguejar de cor (publicado no Brasil com o título a invenção do cemitério) e termina com o livro de poesia mundo blue ou o poema em quarentena. Em comum, o húmus que os compõem, uma certa obsessão, na verdade, a interpretação do mundo e o estudo dos homens que o habitam.

P.: De uma maneira geral, mundo grave é um exemplar da ficção detetivesca, policialesca, tangencia as narrativas centradas em serial killers, nutre-se do animismo e, por ter seu final "inconcluso", pode ser visto em parte com 
representante da literatura fantástica. Seria este mais um aspecto over do romance?

R.: Eu imaginei o mundo grave como um conjunto de três livros, talvez, por isso, as diversas pontas soltas. Hoje, não sei se os irei escrever. Tenho os romances concebidos na minha cabeça, só não tenho o espírito para revisitar o monstro que criei. Não tenho sorte nem sequer oportunidade.

Em todo o seu novelo narrativo, mundo grave não apresenta certezas. O narrador fictício está em constante guerra com o narrador físico, os personagens nunca estão certos de suas crenças, daí que a realidade e o insólito das descrições dependem dos referenciais do leitor, apenas ele é mestre. Assim, é leitor e também parte integrante das histórias. Eu imaginei a narrativa como um ouroboros, onde o princípio e fim da realidade e da fantasia (dentro da ficção) se confundem.

P.: Seja como autor (aquele que escolheu as regras do jogo lúdico a ser jogado com o leitor), seja como crítico (quem é capaz de observar e avaliar algo, parte por parte, e emitir critérios de valor), você alocaria seu mundo grave em alguma dessas categorias ficcionais que elencamos?

R.: mundo grave não chega a ser um típico romance de detective ou de polícia, é antes uma mistura dos dois. Eu não queria nada parecido com o Sherlock, o Poirot ou o Alex Cross; Jaime Bunda, o agente secreto do Pepetela, foi o meu molde, é um policial real, uma autêntica caricatura da polícia africana ou moçambicana. Mas o Jaime Bunda representa, também, um paradigma vigente que não me deixava confortável. Ainda que 
eu goste de pensar no mundo grave como uma narrativa noir, cabe aos críticos dissecá-lo. Esta é a menor das preocupações de um escritor.

P.: Kanova e o segredo da caveira aparece como literatura infantil tanto no projeto promovido pela parceria da Escola Portuguesa de Moçambique com a Fundação Contos para o Mundo de Barcelona, quanto na série publicada pela Editora Kapulana. No plano da história (o que se conta), a narrativa é, inegavelmente, um exemplar dedicado ao público-leitor infantil. Mas sua leitura como conjunto, como objeto-livro, deixou-nos algumas dưvidas. Queriamos ir a elas.

A primeira delas se refere à entrada bastante peremptória, sem qualquer preparo, físico ou textual, d'o conto na sua forma original, que nos pareceu pouco ou nada apropriado à criança leitora. Esta seria uma visão preconceituosa que nos assolou?

R.: Gosto bastante do Kanova..., como livro, não só pelas alegrias que me trouxe (pelas críticas positivas e por figurar, desde 2017, no Plano Nacional de Leitura de Portugal), mas também pela sua composição. É um livro que marca a minha transição de uma escrita ingénua para um labor mais conceptista.

O Kanova... é o quinto livro da colecção "Contos e Histórias de Moçambique". Quando fui convidado para escrevê-lo, era mister que eu lesse os outros, as publicações anteriores, e os achei muito fiéis às histórias originais. Eu sempre tive uma ideia muito cinemática da literatura, de tal modo que escrevi o livro que gostaria de ter lido. 
P.: A segunda delas se refere à sua explicação acerca da origem de Kanova e o segredo da caveira. Do mesmo modo como aparece o conto na sua forma original, a maneira como surge a explicação não estaria dissonante da expectativa que temos quando pensamos no público-leitor infantil?

R.: A colecção já tinha um formato, o número de páginas e as partes do livro foram-me impostas. Fiz, de certa forma, como os outros autores já tinham feito (Mia Couto, Marcelo Panguana, Ungulani, Rogério Manjate, etc.).

P.: Mantendo-nos na seara da literatura infantil, sem nos afastarmos das provocações de antes, em Moçambique, como no Brasil e em Portugal, por exemplo, é indissociável falar de formação de leitor, de ensino de leitura, de espaço familiar, de espaço escolar, quando se fala de literatura infantil?

R.: Não propriamente. Em Moçambique, a literatura infantil sempre foi uma literatura marginal, com quase nenhum incentivo e uma insignificante presença no espaço escolar. Ela sempre ficou fora dos movimentos literários ou gerações de escritores. Nunca fez parte das revistas reservadas aos escritores ou à literatura. Quando saíssem publicações do tipo, eram, na maioria, financiadas pelas ONGs internacionais e, geralmente, com alto teor pedagógico, e eram distribuídas gratuitamente. Até hoje, os textos "infantojuvenis" que aparecem nos livros de ensino são os de proveniência oral, quase que a complementar a ideia das histórias em volta da fogueira. É um nicho em crescimento e com inúmeros desafios em relação ao cânone literário local. 
P.: No Brasil e em Portugal, é extremamente raro ler ou ouvir um estudioso da literatura infantil referindo-se ao texto. 0 mais comum é referir-se ao livro. Nós vemos isso como um grave e absurdo equívoco, pois, antes de mais nada, literatura é texto, ficção é texto, em seu sentido abrangente. Como isso se dá em Moçambique?

R.: Não existem estudiosos de literatura infantil em Moçambique. A existir, então confesso a minha ignorância nesse sentido. Ainda está por se introduzirem disciplinas de literatura infantil nos cursos de educação e letras. É triste.

P.: Tendo-se em vista o que vamos chamar, sem preconceito e sem pudor, de espaços, bem como de realidades, tribais, como pensar a representação ficcional desses espaços e dessas realidades na ficção que tem a criança como sujeito (e não estamos nos referindo, especificamente, a leitor)?

R.: Não creio que esta seja uma preocupação minha ou de outros autores para crianças em Moçambique. Obviamente que o meu primeiro contacto com a literatura infantil foi através das histórias que me eram contadas em casa. Mais tarde, quando comecei a ler, também não vi essa preocupação com o lugar ou com a tribo em Angelina Neves, Machado da Graça ou Mia Couto, que escreveram bastante para crianças. Os "textos" da tradição oral concentravam-se mais com a moral, com o ensinamento, com a coesão e harmonia dentro da comunidade. A literatura infantil moçambicana nasce, também, sob os auspícios de um projecto de nacionalidade, então, de aceitação e construção do moçambicano. Aliás, nessa altura, dizia Samora Machel, que era "preciso matar a tribo para nascer a nação". 
P.: A pergunta anterior talvez não se tenha clarificado. Pensemos em seu Kanova e o segredo da caveira, não no livro, mas no conto em si. O "lugar" dele é a escola? O sujeito a que ele se dirige é o leitor em formação familiar/escolar?

R.: Para o contexto de Moçambique, não sei se há como prever isso, o "lugar" do e para o conto em si. Então, a minha resposta pode não ser a esperada. Entretanto, o projecto original visava fazer chegar o livro às mãos das crianças, em especial nas escolas públicas e centros infantis sem recursos. Em paralelo, a editora criou um outro projecto, "Mabuko Ya Hina" (Os nossos livros), que oferece maletas de livros e introduz actividades que fomentam o hábito de leitura, como concursos de adaptação dramática dos textos.

P.: Como você avalia o momento da ficção moçambicana no que se refere à Literatura infantil?

R.: Como se estivesse a sair, outra vez, de um casulo, mas, principalmente, a recriar-se, a redescobrir-se, com novos autores e afastando-se do paradigma pedagogista.

P.: Como você avalia o momento da ficção moçambicana no que se refere à ficção insólita (maravilhosa, fantástica, realanimista etc.)?

R.: Moçambique é merecidamente uma "Nação de poetas", de modo que a prosa narrativa vai existir em fraca expressão. Actualmente, dois movimentos interessantes se podem notar, o primeiro, a tendência dos escritores canônicos em fazer uma ficção mais histórica (Mia, Ungulani, Adelino Timóteo) ou memorialística (João Paulo Borges Coelho, Paulina Chiziane), e 
a tendência dos escritores mais jovens em experimentar uma ficção mais urbana e actual.

P.: Quais seus planos como ficcionista, sem perder de vista as frentes gloriosas que vem abrindo?

R.: Tenho dois livros em oficina e um terceiro que estará brevemente nas livrarias. Em oficina está um livro de contos curtos, que são uma alegoria das histórias contadas em volta da fogueira; e o outro é um romance juvenil, uma fábula distópica escrita em 2017, sobre o fim dos tempos. O livro a sair é um picture-book co-escrito com a Angelina Neves e ilustrado pelo brasileiro Mauricio Negro. É um livro sobre a magia do livro.

P.: Que mensagem final deixaria para os leitores de língua portuguesa em geral?

R.: A língua une os povos. As literaturas também.

P.: Que mensagem final deixaria para os leitores brasileiros em particular?

R.: Muito obrigado pelo amor.

P.: Que mensagem final deixaria para os leitores e estudiosos da ficção insólita?

R.: O insólito não se opõe ao real. O insólito é real.

P.: Que mensagem final deixaria para os estudiosos da literatura infantil?

R.: Como escritor, faço apenas literatura, não literatura africana. Aquela entrevista a que nos referimos quando falamos de Mia Couto foi dada por ele e José Eduardo Agualusa. O 
entrevistador, logo de início, diz que "Juntar os cronistas [...] para uma conversa a dois prometia, pois, ser da ordem do realismo mágico. Prometia, e cumpriu." Em meio à entrevista, pergunta-Ihes se se lembram de como se conheceram, há quantos anos são amigos. Agualusa responde que "Uma amiga em comum, a Ana Mafalda Leite, professora de Literaturas Africanas, fez um jantar em casa e convidou-nos: conhecemonos assim." Ana Mafalda não nos ofereceu um jantar, nem nos chamou à sua casa, mas foi ela quem nos pôs em contato. Devemos isso a ela, à nossa amiga Ana Mafalda Leite.

Resta-nos agradecer à Ana Mafalda Leite por nos ter propicado esse momento frutífero, pondo-nos em tão oportuno contato, e a Pedro Pereira Lopes pela rica, proveitosa, útil entrevista que nos concedeu, sem fugir de qualquer das muitas perguntas que lhe fizemos, percorrendo viéses e vielas da literatura e crítica literária. 